Filmförderung und Subventionskontrolle in Deutschland 
Springer Results richtet sich an Autoren, die ihre fachliche Expertise in konzentrierter Form präsentieren möchten. Externe Begutachtungsverfahren sichern die Qualität. Die kompakte Darstellung auf maximal 120 Seiten bringt ausgezeichnete Forschungsergebnisse ,auf den Punkt“.

Springer Results ist als Teilprogramm des Bereichs Springer Research der Marken Springer Gabler, Springer Vieweg, Springer VS und Springer Spektrum besonders auch für die digitale Nutzung von Wissen konzipiert. Zielgruppe sind (Nachwuchs-)Wissenschaftler, Fach- und Führungskräfte. 
Florian Kumb

\section{Filmförderung und Subventionskontrolle in Deutschland}

照 SpringerVS 
Florian Kumb

Frankfurt am Main, Deutschland

ISBN 978-3-658-04867-9

ISBN 978-3-658-04868-6 (eBook)

DOI 10.1007/978-3-658-04868-6

Die Deutsche Nationalbibliothek verzeichnet diese Publikation in der Deutschen Nationalbibliografie; detaillierte bibliografische Daten sind im Internet über http://dnb.d-nb.de abrufbar.

Springer VS

(C) Springer Fachmedien Wiesbaden 2014

Das Werk einschließlich aller seiner Teile ist urheberrechtlich geschützt. Jede Verwertung, die nicht ausdrücklich vom Urheberrechtsgesetz zugelassen ist, bedarf der vorherigen $\mathrm{Zu}$ stimmung des Verlags. Das gilt insbesondere für Vervielfältigungen, Bearbeitungen, Übersetzungen, Mikroverfilmungen und die Einspeicherung und Verarbeitung in elektronischen Systemen.

Die Wiedergabe von Gebrauchsnamen, Handelsnamen, Warenbezeichnungen usw. in diesem Werk berechtigt auch ohne besondere Kennzeichnung nicht zu der Annahme, dass solche Namen im Sinne der Warenzeichen- und Markenschutz-Gesetzgebung als frei zu betrachten wären und daher von jedermann benutzt werden dürften.

Gedruckt auf säurefreiem und chlorfrei gebleichtem Papier

Springer VS ist eine Marke von Springer DE. Springer DE ist Teil der Fachverlagsgruppe Springer Science+Business Media.

www.springer-vs.de 


\section{Inhalt}

Abbildungs- und Tabellenverzeichnis ........................................................

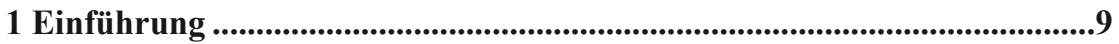

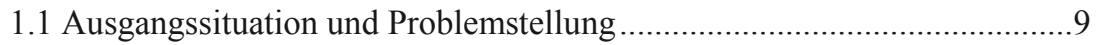

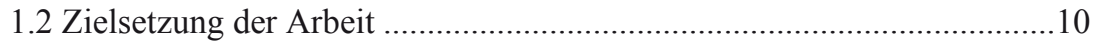

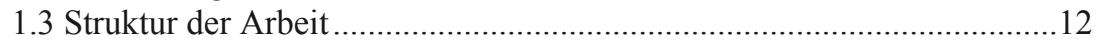

2 Grundlagen der Subventionstheorie ....................................................14

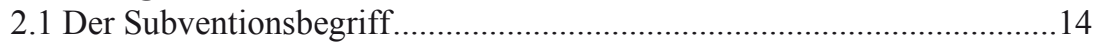

2.2 Argumentative Grundlage und Zielsetzung der Subventionsvergabe......15

2.3 Formen und Wirkungsweisen von Subventionen ..................................17

2.4 Problematik der Subventionskontrolle.......................................................18

3 Rahmenbedingungen der Filmförderung in Deutschland.........................20

3.1 Politische Rechtfertigung und Zielsetzung der Filmförderung ................20

3.1.1 Filmförderung aufgrund von Marktmacht.....................................20

3.1.2 Filmförderung aufgrund meritorischer Eigenschaften ....................21

3.1.3 Filmförderung aufgrund externer Effekte ....................................22

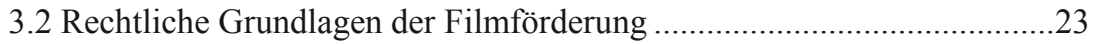

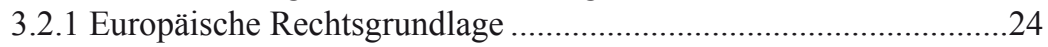

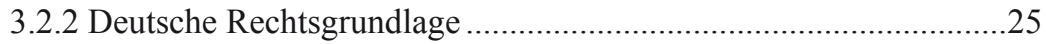

3.3 Ökonomische Bedingungen der Filmförderung ......................................27

3.3.1 Ökonomische Bedingungen des Absatzmarktes ...........................27

3.3.2 Ökonomische Bedingungen des Produktionsmarktes .....................32

3.4 Filmförderungsrelevante technologische Veränderungen..........................34

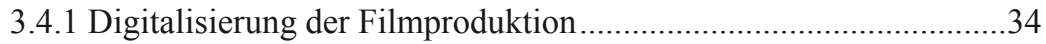

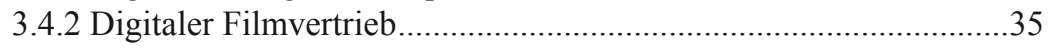

3.5 Filmförderungsrelevante soziokulturelle Restriktionen ............................37

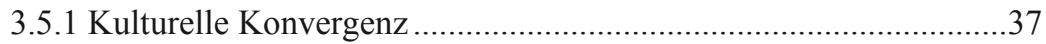

3.5.2 Rezeptionsverhalten von Kultur- und Mediengütern ........................38

4 Neue Politische Ökonomie staatlicher Beihilfen...........................................41

4.1 Grundlagen der Neuen Politischen Ökonomie........................................41 


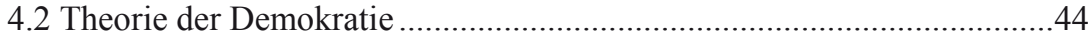

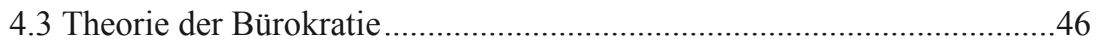

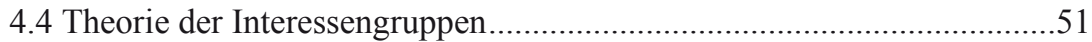

4.5 Kritische Würdigung des Theorieansatzes...........................................54

5 Marktergebnis: Wirkungsmechanismen der Subventionierung ..............56

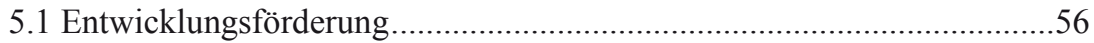

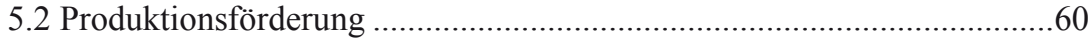

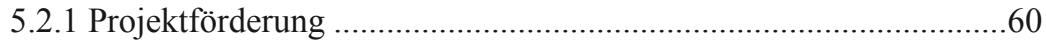

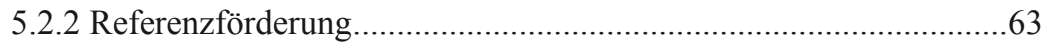

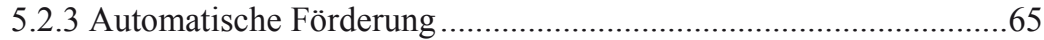

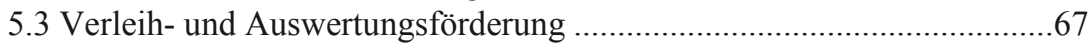

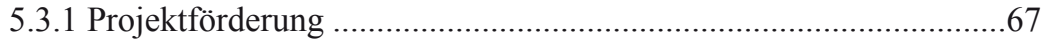

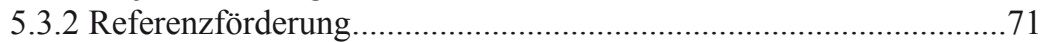

6 Marktverhalten: Ursächliche Partikularinteressen der Akteure .............73

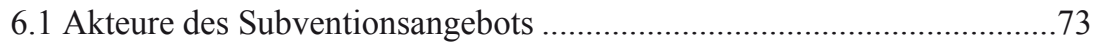

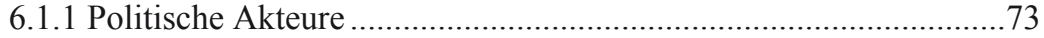

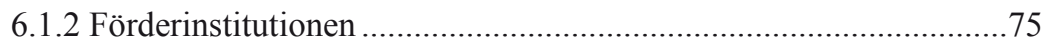

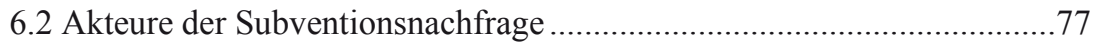

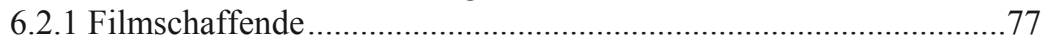

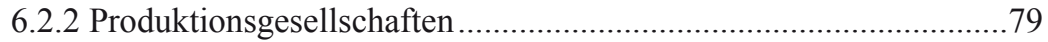

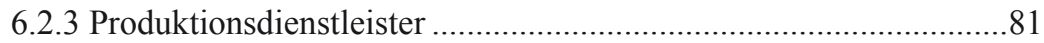

6.3 Akteure beider Marktseiten....................................................................83

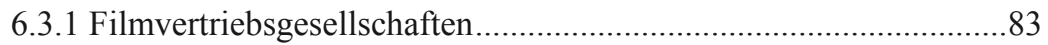

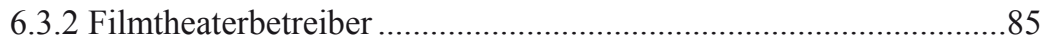

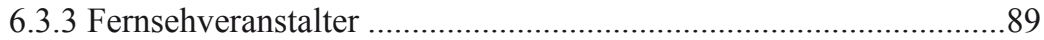

7 Marktstruktur: Auswirkungen auf die Struktur der Filmwirtschaft .....93

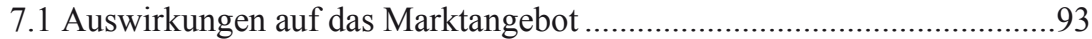

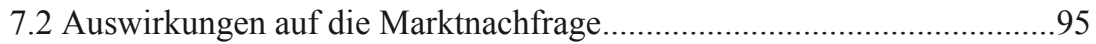

7.3 Auswirkungen auf Marktzutrittsschranken ...........................................97

7.4 Auswirkungen auf den Grad der Produkthomogenität.............................99

8 Fazit und Handlungsimplikationen .....................................................101

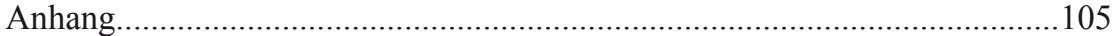

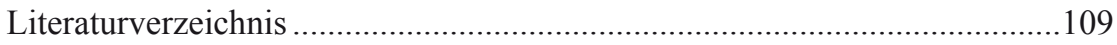




\section{Abbildungs- und Tabellenverzeichnis}

Abbildung 1: Angebot und Nachfrage öffentlicher Güter in der Bürokratietheorie

Abbildung 2: Wirkung der Entwicklungsförderung auf Angebot und Nachfrage

Abbildung 3: Wirkung der Projektfilmförderung auf Angebot und Nachfrage

Abbildung 4: Fördermechanismus der Referenzfilmförderung .....................65

Abbildung 5: Marktauswirkung der Projektabsatzförderung im Inland .........70

Abbildung 6: Marktauswirkung der Projektabsatzförderung im Ausland .....70

Tabelle 1: $\quad$ Arten direkter Subventionen in der Bundesrepublik Deutschland

Tabelle 2: $\quad$ Vergleich der EU-Mitteilungen zur Filmförderung 2001 und 2013

Tabelle 3: $\quad$ Kinoumsätze der Einzelakteure in Deutschland 2012 ..............30

Tabelle 4: $\quad$ Umsätze auf dem deutschen Videomarkt 2012 .......................31

Tabelle 5: $\quad$ Förderinstitutionen und deren Förderleitung 2012 ...................33

Tabelle 6: Durchschnittliche jährliche Kinobesuche der Deutschen

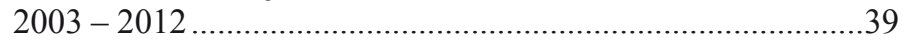

Tabelle 7: $\quad$ Projektverleih- und Auswertungsförderung 2012...................68 